\title{
Kangaroo Care (Skin-to-Skin) for Clustered Pain Procedures: Case Study
}

\author{
Raouth R. Kostandy ${ }^{*}$, Susan M. Ludington-Hoe ${ }^{2}$ \\ ${ }^{1}$ School of Nursing, Cleveland State University, Cleveland, USA \\ ${ }^{2}$ Bolton School of Nursing, Case Western Reserve University, Cleveland, USA \\ Email: *rrkostandy@yahoo.com, Susan.ludington@case.edu
}

Received 22 January 2016; accepted 16 February 2016; published 19 February 2016

Copyright (C) 2016 by authors and Scientific Research Publishing Inc.

This work is licensed under the Creative Commons Attribution International License (CC BY). http://creativecommons.org/licenses/by/4.0/

(c) (i) Open Access

\section{Abstract}

Background: Pain management for term newborns undergoing clustered painful procedures has not been tested. Kangaroo Care (chest-to-chest, skin-to-skin position of infant on mother) effectively reduces pain of single procedures, but its effect on pain from clustered procedures is not known. Aim: The aim was to test Kangaroo Care's effect on pain in one term infant who received clustered painful procedures while determining feasibility of the Kangaroo Care intervention. Design, Setting, and Participant: A case study design was used with one healthy term newborn who received two heel sticks and one injection in one session in the mother's postpartum room. Method: Heart rate and oxygen saturation (recorded from Massimo Pulse Oximeter every 30 seconds), crying time (total seconds of crying on videotape) and behavioral state (using Anderson Behavioral State Scoring system every 30 seconds) were measured before (5 minutes), during (10.5 minutes) and after (30 minutes) the three clustered painful procedures in a newborn who was in Kangaroo Care during all observations. One staff nurse administered the clustered procedures. Results: Heart rate increased sequentially with each heelstick, oxygen saturation remained unchanged, sleep predominated, and crying was minimal throughout the procedures. Conclusion: Kangaroo Care appeared to reduce pain from clustered painful procedures and can be further tested.

\section{Keywords}

Kangaroo Care, Pain, Clustered Procedures, Healthy Term Infant

\section{Introduction}

Newborns can suffer from procedural pain due to Vitamin K and vaccination shots as well as heel sticks for blood sampling (for metabolic screening and blood glucose levels) in the newborn period. Repeated unrelieved

"Corresponding author. 
procedural pain is related to detrimental physiologic and behavioral outcomes [1], including long-term heightened pain or hyperalgesia [2], increased stress sensitivity [3], altered neurobehavioral development [4] [5], and life threatening physiological reactivity [6] [7]. Once newborn perception of pain [8] and negative responsivity to pain [9] became known, the Joint Commission began mandating that interventions to reduce pain be administered with each procedure and that infant response to the intervention be documented [10]. Many pharmacologic and non-pharmacologic interventions are not consistently used due to lack of knowledge about the interventions, their unavailability, and/or perceived impaired effectiveness [11]. Kangaroo Care [KC] (chest-to-chest, skin-toskin contact between mother and infant) is a readily available non-pharmacologic intervention that may relieve pain from clustered painful procedures. Our review of published literature did not yield any reports or studies of KC's use during clustered pain procedures.

\subsection{Problem \& Purpose}

Lack of evidence about KC effects on pain from clustered painful procedures was the problem of the study. The purpose was to determine if KC had any effect on pain responses from clustered procedures (a heel stick for bilirubin, another heel stick for metabolic screening, and then a Hepatitis B vaccination) by conducting a case study with a healthy term infant who was two days old.

\subsection{Significance}

Infant response to clustered pain procedures has not been observed, so the data from the case study provided seminal results to inform definitive studies.

\section{Literature Review}

Several studies investigating the effect of repeated pain procedures were found [12]-[14], but each study tested one painful procedure per day. Investigations of clustered painful procedures during the postnatal period were not found, but one study of clustered painful procedures during infancy was available. Two injections in one session were given to 2 -month old infants after receiving $25 \%$ oral glucose. A significant decrease in crying time and behavioral pain responses occurred with oral glucose [15]. Two other studies were found that measured pain responses to clustered care, not to clustered painful procedures, and both reported heightened behavioral and motor pain responses in preterm infants when given a heel stick immediately after clustered care [16] [17]. A rich evidence-base exists that shows KC is able to reduce the pain of a single procedure. Kangaroo Care relieves pain from one heel stick [18] or one injection [19]. A Cochrane analysis of randomized trials of KC's pain reduction effects in preterm infants showed that $\mathrm{KC}$ is highly effective in reducing the pain associated with one single pain procedure [20]. The same Cochrane review also reported that no studies could be found relating KC's effects on pain responses to two or more painful procedures conducted one right after the other in one session, called clustered pain procedures.

\section{Method}

\subsection{Research Question}

The research question was "What are the infant's pain responses to clustered painful procedures when KC is used as a pain reduction method?"

\subsection{Design \& Setting}

The case reported here was the first subject of a planned pretest (Baseline)-test (clustered painful procedures)posttest (Recovery) randomized controlled trial of KC effects on pain with clustered painful procedures (heel stick(s) + injection in one session). After consent, a sealed envelope revealed assignment to KC during the clustered painful procedures occurring on the postpartum unit. Thus, the design for the case study was a pretest-test-posttest report of one full term, healthy newborn infant who had appropriate weight for her gestational age and who was provided KC by her mother. The study was conducted at an urban, tertiary level maternity unit in central Ohio. Kangaroo Care in the delivery room was not given. The infant received a vitamin $\mathrm{K}$ injection in the delivery room and was to have a Hepatitis B vaccination after 24 hours of age. Hospital policy mandates that 
infants receive all painful procedures at the same time, so a heel stick for metabolic screening was scheduled with the Hepatitis B injection. If subcutaneous bilirubin was positive, additional blood for serum bilirubin was to be collected during the heel stick procedure; this mandate did apply to the subject of the case study. Hospital and University Institutional Review Board approvals were obtained. The mother eagerly gave signed informed consent.

\subsection{Subjects}

The 29 year old white mother had had three previous pregnancies resulting in two live births prior to the birth of this daughter by cesarean section at 39 weeks of gestation (full term). The newborn girl weighed 3700 grams and the one and five minute APGAR scores (scores of infant medical status) were 9 and 9 . The mother had a college degree, was not a smoker, and had no history of drug abuse.

\subsection{Procedure}

After consent, on the day during which the infant was to be given a heel stick for metabolic screening and an injection for Hepatitis B vaccine, the staff nurse conducted a subcutaneous bilirubin check. The bilirubin check was positive, indicating that a serum bilirubin was needed and would require a heel stick, too. The video camera was set-up while the mother was assisted into a 30 - 45 degree upright position. The infant wore only a diaper, and was transferred into KC (prone placement skin-to-skin, chest-to-chest with the mother and covered by a receiving blanket folded over once). A warming pad was placed over the left heel of the infant and left in place for 10 minutes while mother and infant relaxed in KC, as recommended [21]. A Massimo Radical 7 pulse oximeter was attached to the infant's right hand and displayed heart rate (HR) and oxygen saturation $\left(\mathrm{SaO}_{2}\right)$ level on the screen. A Sony video camera was placed on a tripod with the focus on the infant as she laid in KC and was positioned such that the face and body movements beneath blankets could be observed. The video recorded audio and visual information and was used by one research nurse to score the highest level of behavioral state obtained over the prior 30 second interval, continuing throughout each period, using the 12-state Anderson Behavioral State Scoring system (ABSS). Behavioral state means that the state of consciousness of the infant is determined from behavioral characteristics rather than through electroencephalographic characteristics. The ABSS consists of 12 categories that describe the neonate's behavioral state (actions of neonates in response to their internal and external environment). The ABSS is a nominal observational scoring system of 12 mutually exclusive categories of neonatal behavioral state: 1 = Quiet Regular Sleep, 2 = Quiet Irregular Sleep, 3 = Active Sleep, 4 = Very Active Sleep, 5 = Drowsy, 6 = Alert Inactivity, $7=$ Quiet Awake, $8=$ Active Awake, $9=$ Very Active Awake, $10=$ Fussing, $11=$ Crying, and $12=$ Hard Crying. State 12 (Hard Crying) is the highest state level. The ABSS has been used extensively [22] and has established concurrent validity and reliability between 0.71 and 0.95 [23][25]. Baseline data collection lasted five minutes, beginning at the end of the 10 minutes KC time with the mother and ending when the staff nurse performing the heel sticks and giving the injection came to the infant. As soon as the nurse finished adjusting the infant's position from upright chest-to-chest to an oblique chest-tochest lie for easy access to the infant's heel, the test period began. The staff nurse then withdrew the infant's left foot from the wrap covering the infant's body, removed the warming wrap from the heel, positioned the heel between her fingers and used a spring-loaded lancet for the first heel stick. The heel was squeezed for the bilirubin sample and some of the metabolic screening sample. A second heel stick at the same site was needed to saturate all five of the metabolic screening circles on the test strip. As soon as the circles were completely saturated, the test strip was put down and gauze was wrapped around the heel. Then the infant's upper leg was removed from beneath the wrap, wiped with alcohol and injected. Next, the leg was replaced under the wrap and the mother was told that the procedure was over. The mother then repositioned the infant upright between her breasts. The test period was then over and had lasted ten minutes. The post-test period began as soon as the mother had positioned her infant after the procedures and continued for 30 minutes to capture peak response to pain which occurs 20 - 30 minutes after the painful stimulus [22] and to determine when physiologic responses returned to Baseline.

Heart rate and oxygen saturation level were continuously recorded by Massimo Radical 7 pulse oximeter and downloaded into a laptop; behavioral state was assessed every 30 seconds by a research nurse trained to 0.95 reliability on the 12-state Anderson Behavioral State Scoring system, and crying time was measured in seconds by stopwatch run by a second research nurse. Crying was defined as audible whimpering or crying. To determine 
the infant's behavioral state, the videotape of the infant was continually observed throughout multiple 30 second intervals and the highest level of arousal within each interval was scored ("Quiet Alert" was always scored “Quiet Alert”). Data were analyzed using SPSS Version 19.

\section{Results}

\section{Baseline Period (5 minutes)}

During Baseline, the infant's HR ranged from 128 - $134 \mathrm{bpm}(\mathrm{M}=131.40$, $\mathrm{SD}= \pm 1.89)$, oxygen saturation was $97 \%$ - 98\% $(M=97.30$; $S D= \pm 0.48)$, the infant was consistently in Quiet Regular Sleep, and did not cry at all.

\section{Heel Stick Period (2 sticks $=10$ minutes)}

Heel stick \#1. The infant did not cry with the heel stick and remained asleep for the first 4 minutes of the heel stick procedure. After 4.5 minutes of heel squeezing, the baby began to cry. As the squeezing continued, the infant's cry escalated into a lusty cry (ABSS = 12). Throughout heel stick \#1, HR ranged from 129 - $183(\mathrm{M}=$ 146.93; $\mathrm{SD}= \pm 15.01)$ and oxygen saturation ranged from $92 \%-99 \%(\mathrm{M}=97.43, \mathrm{SD}= \pm 1.69)$. Oxygen saturation dropped to $92 \%$ during one 30 -second period of squeezing and recovered to $97 \%$ within 30 seconds. Behavioral state ranged from 1 (Quiet Regular Sleep) to 12 (Hard Cry). The infant was in a sleep state $57.14 \%$ of the time: 8 observations of Quiet Regular Sleep and one observation of Active Sleep. The infant was in the Crying (4 observations, 28.56\%) or Hard Crying (2 observations, 14.29\%) state for a total of $42.8 \%$ of the time. Crying time was 51.0 seconds during Heel Stick \#1.

Heel Stick \#2. Because blood collection was insufficient to complete the metabolic screen, a second heel stick was performed. Heel stick \#2 occurred at seven minutes into the Heel Stick period, and was performed in the same area as heel stick \#1. Infant HR ranged between $148-168 \mathrm{bpm}(\mathrm{M}=159.83$, SD = \pm 7.13$)$ and oxygen saturation was $97 \%$ - 98\% ( $M=97.33, \mathrm{SD}= \pm 0.51)$. The infant was only once in the Fussy state, calmed down and was in Active Awake state twice, followed by the Quiet Regular Sleep state three times as the bandage was applied. Crying time during heel stick \#2 was 10 seconds.

\section{Injection Period (30 seconds)}

During the Injection period, HR and oxygen saturation were measured once and HR was154 bpm and oxygen saturation was 98\%. The infant went from Quiet Regular Sleep to Hard Crying with the injection, and crying time was 18 seconds.

\section{Recovery Period (30 minutes)}

Heart rate range was $131-154 \mathrm{bpm}(\mathrm{M}=139.08, \mathrm{SD}= \pm 5.12) ; \mathrm{SaO}_{2}$ was $94 \%-98 \%(\mathrm{M}=97.48$, $\mathrm{SD}=$ \pm 0.81 ). Quiet Regular Sleep predominated (50/60 observations or $83.33 \%$ of the time); Quiet Irregular Sleep or Active Sleep occurred $16.66 \%$ of the time, and no crying time was recorded.

\section{Feasibility}

The mother reported no difficulty in maintaining KC throughout all the procedures and commented that the infant did not squirm at all or change her position.

\section{Discussion}

A two-day-old healthy full term female received two heel sticks and one injection, one right after the other, during one session of $\mathrm{KC}$ and showed reduced pain responses ( $\mathrm{HR}, \mathrm{SaO}_{2}$, behavioral state, crying time) to each sequential pain experience throughout two heelsticks (10 minutes), injection (30 seconds), and recovery (30 minutes) periods. Each painful procedure increased the infant's heart rate above Baseline: the second heel stick increased her heart rate more than the first heel stick, but heart rate was not as greatly increased during the injection ( $3^{\text {rd }}$ painful procedure). Oxygen saturation did not decrease with any heel stick or injection and only dropped once (by 5\%) during squeezing at the end of the first heel stick, so stability in $\mathrm{SaO}_{2}$ predominated. Crying time was longest during the first heel stick, shorter with the second heel stick, and was longer again with the 30-second injection. The infant was predominantly in a sleep state during each period and aroused to a crying state with squeezing during the first heel stick and during the injection. Oxygen saturation, crying time, and behavioral state returned to Baseline by the first observation of the Recovery period (indicating a swift recovery), and HR returned to Baseline by minute 5 of Recovery, vacillating slightly thereafter. Even with three consolidated painful procedures, no bradycardia (heart rate $<120 \mathrm{bpm}$ ) nor oxygen desaturation ( $<88 \%$ ) occurred.

Pain-induced changes occurred with each painful procedure, showing 1) similar heart rate data to previous 
results in preterm infants [26] and full term infants [27] receiving heel sticks or injections [28] [29]; 2) similar oxygen saturation findings of relative stability within clinically acceptable ranges during KC [30]; and 3) controversial crying time results in that crying time was longer with the first heel stick than with the second. A shorter cry response to the second heel stick is consistent with previous reports of lower behavioral activity with repeated pain [3]. Crying time during and after the injection was lower than crying time with the previous heel sticks. Shorter injection-based crying time is similar to previous work [31], but that our infant cried at all during the injection in KC is contrary to the findings of [32] Vivancos, Leite, Scochi, and Dos Santos (2010) who found no crying in response to a Hepatitis B injection during KC in 20 term newborns. This difference may be explained by the number of invasive procedures the infants experienced: when the Hepatitis B injection was the one and only invasive procedure [32], crying did not occur, but, when the Hepatitis B injection followed two previous invasive procedures, crying did occur, probably due to heightened arousal and sensitivity to pain. Further, vacillations in crying time indicated an individual inconsistency in crying response to pain across the three invasive procedures, similar to previous work [33]. Our behavioral state findings are similar to those previously reported: the infant was in Quiet Regular Sleep state during Baseline and the first 4.5 minutes after the first heel stick, then escalated to Fussy and Crying states as squeezing continued. Soon after the second heel stick, she went from Fussy state to Quiet Regular Sleep state and stayed in Quiet Regular Sleep state until the injection when state escalated to Hard Crying. [19] Kashaninia et al. (2008) and [34] Kostandy, Anderson, and Good (2013) also reported lusty crying during a Vitamin K or a Hepatitis B vaccine injections conducted during KC. After the injection, our subject's behavioral state swiftly returned to Quiet Regular State and remained in that state until the end of Recovery, similar to other study findings [19] [28]. That all pain parameters returned to Baseline values within the first five minutes of Recovery is similar to previous reports of infants experiencing KC throughout a Recovery period [19] [27] [28] [34]. Because our subject's pain responses were predominantly similar to those of other full term infants' responses to painful stimuli during KC, the role of KC in minimizing infant pain has been confirmed, and KC's role in minimizing clustered pain responses is suggested and merits further investigation.

Increases in each pain response over Baseline clearly indicated pain. A contribution of the data reported here is that the full term infant was able to mount changes in physiologic and behavioral responses to three painful procedures that were clustered together. Interestingly, the third painful procedure, the injection, did not induce as much of an increase in HR and crying time as the first and second heel sticks. The response to the injection may be explained in several ways. The injection may not have been as painful as the heel sticks, which could reflect the larger size of the lancet than the needle. A larger size instrument increases intensity of pain more than a small size instrument [35]. Usually, the larger the incision, the more damage there is to tissue and the pain response is increased [36]. Another possibility is that the injection process was shorter and less complex than the heel stick, because the injection involves insertion of needle, injection of medication, and removal of needle, usually accomplished in 10 seconds, and then the infant is left alone. But, with a heel stick, after the lancet is removed, the foot is not only held longer, but the heel tissue is also squeezed. Squeezing is more painful than the lance [26] and causes different HR and behavioral state responses than the actual lance when analyzed as two distinct phases of a heel stick [26]. Also, the duration of exposure to pain was much shorter with the injection than with the heel sticks. In our study, the injection took 30 seconds and the heel stick procedures took $10 \mathrm{mi}-$ nutes. Brain physiology relates that pain responses are generated within 20 - 40 seconds of a painful stimulus [37]. Her HR started increasing 150 seconds after the heel stick, unlike heart rate rises that occur within 20 seconds of a heel stick without Kangaroo Care [37]. Our data suggest that the pain response to the injection was initiated, but physiologic ( $\mathrm{HR}$ and $\mathrm{SaO}_{2}$ ) and behavioral state return to Baseline was quite quick, within five minutes, again suggesting that the short duration of exposure to pain can facilitate swifter Recovery. Physiologic and behavioral parameters of pain have returned to Baseline within 2 to 20 minutes post-event when term infants have been in Kangaroo Care [19] [27] [28] [34]. Another contributor to pain, other than duration of the painful stimulus, is the number of painful events occurring within a short time frame. The brain's response to one acute painful event may be different than it is to clustered painful events, as can occur with prolonged pain [38]. Presenting three painful procedures one right after the other can be considered prolonged pain [38] and the brain's response to pain may habituate to the last of the clustered procedures. The fact that most pain responses changed the most in response to the first two painful events but not to the third support's Van Dijk's theory of habituated brain response over repeated painful stimuli.

An infant's state at the time of any painful procedure modifies pain response [39]. At the time of the injection, 
the infant was asleep; sleep decreases the number and intensity of painful responses [40]. The infant was also asleep when the first heel stick was conducted and continued to remain asleep for a full four minutes. The intensity of the painful stimulus influences pain response, too. Nurses give the injection last because nurses believe "all babies cry with the injection". Our infant cried 18 seconds out of 30 seconds for the injection, and for 61 seconds out of 10 minutes for the two heel sticks. These data indicate that the injection of vaccine into muscle tissue incurred more crying than heel sticks and squeezes of the epithelium. More crying (and pain) with the third procedure contradicts previous findings [41] which showed that the pain reducing effects of KC increased over time. Kangaroo Care has antinociceptive effects for many reasons [22] [42], one of which is oxytocin release in the brain [43] [44]. Uvnas-Moberg et al.'s work has shown that central oxytocin blocks pain reception, raises the pain threshold and increases release of endogenous opioids to produce antinociception [44]. Pleasant human touch is specifically coded-for in brain areas responsible for minimizing pain perception [45]. Kangaroo Care is pleasing human touch and it modifies infant pain [45] by increasing opioid peptide secretion in infants [46] [47].

Limitations. A limitation of the study was the case study design in which only one subject has been tested. Thus, the results should be interpreted with caution as they reflect only one infant's response to clustered painful procedures and individual infants differ in their pain responses [39]. A case study sets the stage for future research; one must be cautious about making recommendations for practice based on a sample size of one. Another limitation was that the heel stick was done on the infant's left foot, and the left side of term newborns' bodies produce less prefrontal brain activation with pain than the right side of the body [48], indicating study of sticks on both sides of the body is warranted.

Implications. The case study provides an indication that KC may be helpful in managing the pain of clustered painful procedures in full term neonates. Most mother-baby nurses do not know that KC minimizes pain [49]; thus, nursing education needs to include $\mathrm{KC}$ as a non-pharmacologic pain reduction intervention for newborns and infants. In regards to practice, nurses can now be assured that KC can be used to minimize bedside procedural pain [20] [50] and can practice in a way consistent with current best practice recommendations [9] [51]. Also, the mother we studied eagerly participated, suggesting a positive attitude toward holding her infant during the clustered painful procedures; some, but not all, mothers want to hold their infants during painful procedures [52] [53]. Determining and encouraging maternal willingness to do so are recommended.

Kangaroo Care's effectiveness in minimizing pain due to clustered painful procedures needs to be established by adequately powered experimental studies. Future studies could also consider the nurse's level of empathy for the infant's pain because nurse empathy is expected to be related to the magnitude of pain an infant experiences [54]. Future research can also address the possibility that clustered painful procedures may be less painful than single painful procedures.

\section{Conclusion}

This case study of a healthy term female newborn suggests that KC minimizes the pain of clustered painful procedures performed on the left side of the body. Clustered painful procedures were tolerated without bradycardia and oxygen desaturation during KC. Further studies with a larger sample size and experimental designs are needed to establish KC's role in the management of pain from clustered painful experiences.

\section{Conflicts of Interest}

Raouth R. Kostandy reports no financial interest or potential conflicts of interest. Susan M. Ludington-Hoe reports no financial interest or potential conflicts of interest.

\section{Fund}

Financial support for the study was provided in part by The University of Akron, College of Nursing Research Award and The University of Akron Faculty Research Grants and Fellowships and both organizations had no role in execution of the study beyond financial support.

\section{References}

[1] Taddio, A., Shah, V., Gilbert-MacLeod, C. and Katz, J. (2002) Conditioning and Hyperalgesia in Newborns Exposed 
to Repeated Heel Lances. The Journal of the American Medical Association, 288, 857-861. http://dx.doi.org/10.1001/jama.288.7.857

[2] Abdulkader, H.M., Freer, Y., Garry, E.M., Fleetwood-Walker, S.M. and McIntosh, N. (2008) Prematurity and Neonatal Noxious Events Exert Lasting Effects on Infant Pain Behavior. Early Human Development, 84, 351-355. http://dx.doi.org/10.1016/j.earlhumdev.2007.09.018

[3] Grunau, R.E., Holsti, L., Haley, D.W., Oberlander, T., Weinberg, J. and Solimano, A. Whitfield M.F., Fitzgerald, C. and Yu, W. (2005) Neonatal Procedural Pain Exposure Predicts Lower Cortisol and Behavioral Reactivity in Preterm Infants in the NICU. Pain, 113, 293-300. http://dx.doi.org/10.1016/j.pain.2004.10.020

[4] Grunau, R.E., Weinberg, J. and Whitfield, M.F. (2004) Neonatal Procedural Pain and Preterm Infant Cortisol Response to Novelty at 8 Months. Pediatrics, 114, e77-e84. http://dx.doi.org/10.1542/peds.114.1.e77

[5] Holsti, L., Grunau, R.E., Oberlander, T.F. and Whitfield, M.F. (2004) Specific Newborn Individualized Developmental Care and Assessment Program Movements Are Associated with Acute Pain in Preterm Infants in the Neonatal Intensive Care Unit. Pediatrics, 114, 65-72. http://dx.doi.org/10.1542/peds.114.1.65

[6] Anand, K.J.S. (1998) Clinical Importance of Pain and Stress in Preterm Neonates. Biology of the Neonates, 73, 109. http://www.ncbi.nlm.nih.gov/pubmed/?term=Clinical+importance+of+pain+and+stress+in+preterm+neonates http://dx.doi.org/10.1159/000013953

[7] Anand, K.J.S. and Hickey, P.R. (1987) Pain and Its Effects in the Human Neonate and Fetus. The New England Journal of Medicine, 317, 1321-1329. http://dx.doi.org/10.1056/nejm198711193172105

[8] Cignacco, E., Hamers, J.P., Stoffel, L., van Lingen, R.A., Gessler, P., McDougall, J. and Nelle, M. (2007) The Efficacy of Non-Pharmacologic Interventions in the Management of Procedural Pain in Preterm and Term Neonates. A Systematic Literature Review. European Journal of Pain, 11, 129-152. http://dx.doi.org/10.1016/j.ejpain.2006.02.010

[9] Anand, K.J., Aranda, J.V., Berde, C.B., Buckman, S., Capparelli, E.V., Carlo, W., et al. (2006) Summary of Proceedings from the Neonatal Pain-Control Group. Pediatrics, 117, S9-S22.

[10] Joint Commission (2011) Provision of Care, Treatment, and Services (PC). Joint Commission of Accreditation of Health Organizations (JCAHO), Washington DC, Available from Joint Commission Resources, 877-223-6866.

[11] Carbajal, R., Rousset, A., Daanan, C., Coquey, S., Nolent, P., Ducrocq, S., et al. (2008) Epidemiology and Treatment of Painful Procedures in Neonates in Intensive Care Units. Journal of American Medical Association, 300, 60-70. http://dx.doi.org/10.1001/jama.300.1.60

[12] Cignacco, E.L., Sellam, G., Stoffel, L., Gerull, R., Nelle, M., Anand, K.J. and Engberg, S. (2012) Oral Sucrose and “Facilitated Tucking” for Repeated Pain Relief in Preterms: A Randomized Controlled Trial. Pediatrics, 129, 299-308. http://dx.doi.org/10.1542/peds.2011-1879

[13] Gao, H., Xu, G., Gao, H., Dong, R., Fu, H., Wang, D., Zhang, H. and Zhang, H. (2015) Effect of Repeated Kangaroo Mother Care on Repeated Procedural Pain in Preterm Infants: A Randomized Controlled Trial. International Journal of Nursing Studies, 52, 1157-1165. http://dx.doi.org/10.1016/j.ijnurstu.2015.04.006

[14] Gitto, E., Pellegrino, S., Manfrida, M., Aversa, S., Trimarchi, G., Barberi, I. and Reiter, R.J. (2012) Stress Response and Procedural Pain in the Preterm Newborn: The Role of Pharmacological and Non-Pharmacological Treatments. European Journal of Pediatrics, 171, 927-933. http://dx.doi.org/10.1007/s00431-011-1655-7

[15] Kassab, M., Sheehy, A., King, M., Fowler, C. and Foureur, M. (2012) A Double-Blind Randomised Controlled Trial of 25\% Oral Glucose for Pain Relief in 2-Month Old Infants Undergoing Immunization. International Journal of Nursing Studies, 49, 249-256. http://dx.doi.org/10.1016/j.ijnurstu.2011.09.013

[16] Holsti, L., Grunau, R.E., Oberlander, T.F. and Whitfield, M.F. (2005) Prior Pain Induces Heightened Motor Responses during Clustered Care in Preterm Infants in the NICU. Early Human Development, 81, 293-302. http://dx.doi.org/10.1016/j.earlhumdev.2004.08.002

[17] Holsti, L., Grunau, R.E., Whifield, M.F., Oberlander, T.F. and Lindh, V. (2006) Behavioral Responses to Pain Are Heightened after Clustered Care in Preterm Infants Born between 30 and 32 Weeks Gestational Age. Clinical Journal of Pain, 22, 757-764. http://dx.doi.org/10.1097/01.ajp.0000210921.10912.47

[18] Bulfone, G., Nazzi, E. and Tenore, A. (2011) Kangaroo Mother Care and Conventional Care: A Review of the Literature. Professioni Infermieristiche, 64, 75-82. http://profinf.net/pro/index.php/pi

[19] Kashaninia, Z., Sajedi, F., Rahgozar, M. and Noghabi, A. (2008) The Effect of Kangaroo Care on Behavioral Responses to Pain of an Intramuscular Injection in Neonates. Journal for Specialists in Pediatric Nurses (JSPN), 13, 275280. http://dx.doi.org/10.1111/j.1744-6155.2008.00165.x

[20] Johnston, C.C., Campbell-Yeo, M., Fernandes, A., Inglis, D., Streiner, D. and Zee, R. (2014) Skin-to-Skin Care for Procedural Pain in Neonates. Cochrane Database of Systematic Reviews, Issue 1, Article No. CD008435. http://dx.doi.org/10.1002/14651858.cd008435.pub2

[21] Gray, L., Watt, L. and Blass, E. (2000) Skin-to-Skin Contact Is Analgesic in Healthy Newborns. Pediatrics, 105, e14- 
e24. http://pediatrics.aappublications.org/content/105/1/e14.full.pdf+html http://dx.doi.org/10.1542/peds.105.1.e14

[22] Ludington-Hoe, S.M., Hosseini, R.B. and Torowicz, D.L. (2005) Skin-to-Skin Contact (Kangaroo Care) Analgesia for Preterm Infant Heel Stick. American Association of Critical-Care Nurses Clinical Issues, 16, 373-387. http://www.ncbi.nlm.nih.gov/pmc/articles/PMC1890009/ http://dx.doi.org/10.1097/00044067-200507000-00010

[23] Gill, N., Behnke, M., Conlon, M., McNeely, J. and Anderson, G. (1988) Effect of Nonnutritive Sucking on Behavioral State in Preterm Infants before Feeding. Nursing Research, 37, 347-350. http://dx.doi.org/10.1097/00006199-198811000-00007 http://journals.lww.com/nursingresearchonline/pages/default.aspx

[24] Gill, N.E., Behnke, M., Conlon, M. and Anderson, G.C. (1992) Nonnutritive Sucking Modulates Behavioral State for Preterm Infants before Feeding. Scandinavian Journal of Health and Caring Sciences, 6, 3-7. http://dx.doi.org/10.1111/j.1471-6712.1992.tb00115.x

[25] McCain, G.C. (1992) Facilitating Inactive Awake States in Preterm Infants: A Study of Three Interventions. Nursing Research, 41, 157-160. http://journals.lww.com/nursingresearchonline/pages/default.aspx http://dx.doi.org/10.1097/00006199-199205000-00006

[26] Cong, X., Ludington-Hoe, S.M., McCain, G. and Fu, P. (2009) Kangaroo Care Modifies Preterm Infant Heart Rate Variability in Response to Heel Stick. Early Human Development, 85, 561-567. http://dx.doi.org/10.1016/j.earlhumdev.2009.05.012

[27] Okan, F., Ozdil, A., Bulbul, A., Yapici, Z. and Nuhoglu, A. (2010) Analgesic Effects of Skin-to-Skin Contact and Breastfeeding in Procedural Pain in Healthy Term Neonates. Annals of Tropical Pediatrics, 30, 119-128. http://dx.doi.org/10.1179/146532810X12703902516121

[28] Chermont, A.G., Falcao, L.F., de Souza Silva, E.H., de Cassia Xavier Balda, R. and Guinsburg, R. (2009) Skin-to-Skin Contact and/or Oral 25\% Dextrose for Procedural Pain Relief for Term Newborn Infants. Pediatrics, 124, e1101e1107. http://dx.doi.org/10.1542/peds.2009-0993

[29] Sajedi, F., Kashaninia, Z., Rahgozar, M. and Noghabi, F. (2007) The Effect of Kangaroo Care on Physiologic Responses to Pain of an Intramuscular Injection in Neonates. Iranian Journal of Pediatrics, 17, 339-344. http://ijp.tums.ac.ir/index.php/ijp/article/view/708/706

[30] de Sousa Freire, N.B., Garcia, J.B.S. and Lamy, Z.C. (2008) Evaluation of Analgesic Effect of Skin-to-Skin Contact Compared to Oral Glucose in Preterm Neonates. Pain, 139, 28-33. http://dx.doi.org/10.1016/j.pain.2008.02.031

[31] Abdel Razek, A. and Az El-Dein, N. (2009) Effect of Breast-Feeding on Pain Relief during Infant Immunization Injections. International Journal of Nursing Practice, 15, 99-104. http://dx.doi.org/10.1111/j.1440-172X.2009.01728.x

[32] Vivancos, R.B.Z., Leite, A.M., Scochi, C.G.S. and Dos Santos, C.B. (2010) The Skin to Skin Contact at Birth and Newborn Crying during Vaccination against Hepatitis B. Acta Paulista de Enferemagem, 23, 461-465.

http://www.redalyc.org/pdf/3070/307023863003.pdf http://dx.doi.org/10.1590/S0103-21002010000400003

[33] Cignacco, E., Denhaervnck, K., Nelle, M., Buhrer, C. and Engberg, S. (2009) Variability in Pain Response to a Non-Pharmacologic Intervention across Repeated Routine Pain Exposure in Preterm Infants: A Feasibility Study. Acta Paediatrica, 98, 842-846. http://dx.doi.org/10.1111/j.1651-2227.2008.01203.x

[34] Kostandy, R.R., Anderson, G.C. and Good, M. (2013) Skin-to-Skin Contact Diminishes Pain from Hepatitis B Vaccine Injection in Healthy Full-Term Neonates. Neonatal Network, 32, 274-280. http://dx.doi.org/10.1891/0730-0832.32.4.274

[35] Bergqvist, L.L., Katz-Salamon, M., Hertegård, S., Anand, K.J. and Lagercrantz, H. (2009) Mode of Delivery Modulates Physiological and Behavioral Responses to Neonatal Pain. Journal of Perinatology, 29, 44-50. http://dx.doi.org/10.1038/jp.2008.129

[36] Celestre, P.C., Pazmino, P.R., Mikhael, M.M., Wolf, C.F., Fedlman, L.A., Laurysssen, C. and Wang, J.C. (2012) Minimally Invasive Approaches to the Cervical Spine. Orthopedic Clinics of North America, 43, 137-147. http://dx.doi.org/10.1016/j.ocl.2011.08.007

[37] Bartocci, M., Bergqvist, L.L., Lagercrantz, H. and Anand, K.J. (2006) Pain Activates Cortical Areas in the Preterm Newborn Brain. Pain, 122, 109-117. http://dx.doi.org/10.1016/j.pain.2006.01.015

[38] van Dijk, M., Roofthooft, D.W., Anand, K.J., Guldemond, F., de Graaf, J., Simons, S., de Jager, Y., van Goudoever, J.B. and Tibboel, D. (2009) Taking up the Challenge of Measuring Prolonged Pain in (Premature) Neonates: The COMFORTneo Scale Seems Promising. Clinical Journal of Pain, 25, 607-616. http://dx.doi.org/10.1097/AJP.0b013e3181a5b52a

[39] Johnston, C.C., Fernandes, A.M. and Campbell-Yeo, M. (2011) Pain in Neonates Is Different. Pain, 152, S65-S73. 
http://dx.doi.org/10.1016/j.pain.2010.10.008

[40] Mathai, S.S., Naresh, A. and Sahu, S. (2011) Behavioral Response to Pain in Drowsy and Sleeping Neonates: A Randomized Control Study. Indian Pediatrics, 48, 390-392. http://www.indianpediatrics.net/may2011/390.pdf http://dx.doi.org/10.1007/s13312-011-0082-1

[41] Morelius, E., Theodorsson, E. and Nelson, N. (2005) Salivary Cortisol and Mood and Pain Profiles during Skin-to-Skin Care for an Unselected Group of Mothers and Infants in Neonatal Intensive Care. Pediatrics, 116, 1105-1113. http://dx.doi.org/10.1542/peds.2004-2440

[42] Parsons, C.E., Young, K.S., Murray, L., Stein, A. and Kringelbach, M.L. (2010) The Functional Neuroanatomy of the Evolving Parent-Infant Relationship. Progress in Neurobiology, 91, 220-241. http://dx.doi.org/10.1016/j.pneurobio.2010.03.001

[43] Bystrova, K. (2009) Novel Mechanism of Human Fetal Growth Regulation: A Potential Role of Lanugo, Vernix Caseosa and a Second Tactile System of Unmyelinated Low-Threshold C-Afferents. Medical Hypotheses, 72, $143-146$. http://dx.doi.org/10.1016/j.mehy.2008.09.033

[44] Uvnas-Moberg, K., Arn, I. and Magnusson, D. (2005) The Psychobiology of Emotion: The Role of the Oxytocinergic System. International Journal of Behavioral Medicine, 12, 59-65. http://www.ncbi.nlm.nih.gov/pubmed/15901214 http://dx.doi.org/10.1207/s15327558ijbm1202 3

[45] Lindgren, L., Wrestling, G., Bruin, C., Lehtipalo, S., Andersson, M. and Nyberg, L. (2012) Pleasant Human Touch Is Represented in Pregenual Anterior Cingulated Cortex. Neuroimage, 59, 3427-3432. http://dx.doi.org/10.1016/j.neuroimage.2011.11.013

[46] Weller, A. and Feldman, R. (2003) Emotion Regulation and Touch in Infants: The Role of Cholecystokinin and Opioids. Peptides, 24, 779-788. http://dx.doi.org/10.1016/S0196-9781(03)00118-9

[47] Weller, A., Rozin, A., Goldstein, A., Charpak, N., Ruis-Pelaez, J.G., Figueroa de Calume, Z., Charpak, Y. and Sack, J. (2002) Longitudinal Assessment of Pituitary-Thyroid Axis and Adrenal Function in Preterm Infants Raised by "Kangaroo Mother Care”. Hormone Research, 57, 22-26. http://dx.doi.org/10.1159/000057942

[48] Ozawa, M., Kanda, K., Hirata, M., Kusakawa, I. and Suzuki, C. (2011) Effect of Gender and Hand Laterality on Pain Processing in Human Neonates. Early Human Development, 87, 45-48. http://dx.doi.org/10.1016/j.earlhumdev.2010.09.371

[49] Mallet, I., Bomy, H., Govaert, N., Goudal, I., Brasme, C., Dubois, A., Boudringhien, S. and Pierrat, V. (2007) Skin to Skin Contact in Neonatal Care: Knowledge and Expectations of Health Professionals in 2 Neonatal Intensive Care Units. Archives de Pediatrie, 14, 881-886. http://www.sciencedirect.com/science/article/pii/S0929693X07001820 http://dx.doi.org/10.1016/j.arcped.2007.01.017

[50] Campbell-Yeo, M., Fernandes, A. and Johnston, C. (2011) Procedural Pain Management for Neonates Using Nonpharmacological Strategies: Part 2: Mother-Driven Interventions. Advances in Neonatal Care, 11, 312-318. http://dx.doi.org/10.1097/ANC.0b013e318229aa76

[51] American Academy of Pediatrics and Canadian Pediatric Society (2006) Prevention and Management of Pain in the Neonate: An Update. Pediatrics, 118, 2231-2241. http://dx.doi.org/10.1542/peds.2006-2277

[52] Axelin, A., Lehtonen, L., Pelander, T. and Salanterä, S. (2010) Mothers’ Different Styles of Involvement in Preterm Infant Pain Care. Journal of Obstetrics, Gynecology, \& Neonatal Nursing, 39, 415-424. http://dx.doi.org/10.1111/j.1552-6909.2010.01150.x

[53] Boukydis, Z. (2011) Parent-Infant Skin-to-Skin Contact: Parents’ Views versus Nurses’ Views. Acta Paediatrica, 100, 638-640. http://dx.doi.org/10.1111/j.1651-2227.2011.02195.x

[54] Latimer, M., Jackson, P., Johnston, C. and Vine, J. (2011) Examining Nurse Empathy for Infant Procedural Pain: Testing a New Video Measure. Pain Research and Management, 16, 228-233.

http://www.ncbi.nlm.nih.gov/pmc/articles/PMC3202373/ 